was very soft and flabby and the left ventricular wall was quite lax and the cavity was somewhat dilated. The epicardium looked opaque and thickened in places and the endocardium and intima of the pulmonary artery and aorta showed a considerable degree of post-mortem staining. The muscle of the left ventricular wall was very soft and friable, of a pale reddish-brown colour, with slight yellowish and grey streaking. Under the microscope there was slight brown atrophy and also granular degeneration of the myocardium, while there was a distinct increase in the interstitial fibrous tissue. There were no valvular lesions. The liver was slightly enlarged, congested, and very soft and flaccid. On section the liver substance looked swollen, cloudy and opaque, and mottled with congestion and with shades of a greyish-brown colour. Sections examined under the microscope showed a slight degree of fatty infiltration of the peripheral zone, congestion and dilatation of the intercellular capillary spaces in the central zone of the lobules. The liver cells were swollen, much vacuolated, and likewise coarsely granular and fatty (osmic acid preparations). The stomach was empty, the gastric mucous membrane was coated with a gelatinous mucoid secretion, beneath there was both post-mortem staining and also ante-mortem congestion and ecchymosis; the rugæ were flattened. The mucous membrane of the intestinal canal was much congested in parts ; the intestinal contents were a brownish liquid fæces in which mucous shreds and flocculi of mucus were mingled. The condition was that of gastro-enteritis. The spleen was enlarged, soft, and deeply congested. The kidneys were slightly enlarged; both were quite soft and flaccid. The capsules were slightly adherent in places. On section the medullary cones were purplish and deeply hyperæmic, the cortex looked swollen, of a pale brown or fawn colour, but variegated by a striated and punctiform congestion, and here and there showing a greyish yellow tint. Histological examination showed a well-marked parenchymatous nephritis. The tubuli contorti were blocked by swollen and granulo-fatty epithelial cells; in other tubules both in the cortex and medullary rays were found leucocytes and occasionally red blood cells, while others again contained here and there a hyaline or cellular cast. Another noticeable change was a general thickening of branches of the renal artery affecting the intima (endarteritis) as well as the muscularis and adventitia; the arterioles in the boundary layer also looked to be thickened. The fibrous capsule of the kidney was also irregularly thickened; there was thickening of the intertubular stroma. The uterus was enlarged to about the size of a large pear, the mucous membrane was thickened, soft and congested, and adhering to it were one or two coagula. It presented all the evidences of recent abortion, but otherwise the organ was quite healthy and nowhere either in its walls or around them was there the slightest evidence of inflammatory mischief.

Remarks.-My first acquaintance with mania as the result of lead-poisoning was made in Germany some fourteen years ago where I saw in an asylum at Dresden patients who had suffered from the effects of it. I met with other cases subsequently and only a year or two ago in the Potteries; and one of these cases is so similar in regard to symptoms and termination to this case that I will relate it. I was called to a middle-aged woman-an old and valued hand employed at one of the principal porcelain factories-who was said to have suddenly gone mad, after complaining a week or so of feeling unwell. I found her raving in a maniacal manner, struggling violently and held down by three or four women. There was an earthy pallor of the face, a well-marked blue line along the free border of the gums, offensive breath, furred and parched tongue, and as she had been working in lead in the glazing department I concluded that she was suffering from acute mania resulting from lead-poisoning. I obtained the assistance of a magistrate and the relieving officer, certified her, and she was removed straightway to the Stafford County Asylum, where she died, as I was informed, two days afterwards with much the same symptoms as the preceding patient.

In regard to the connexion of lead-poisoning with abortion I have heard of cases of miscarriage in women in the Potteries who became the victims of lead-poisoning. Some years ago the town of Sheffield was visited by an outbreak of lead-poisoning traced to the contamination of the water-supply, and I remember at the time it was noted that pregnant women who became affected either aborted or had a premature labour. I have reason to suspect that in this district the practice of taking diachylon in the form of pills to bring on miscarriage is far more prevalent among the working-class than is generally supposed. About eighteen months ago a patient came to me looking wretchedly ill, who admitted having taken diachylon for the purpose. After warning her of the serious consequences which might follow I prescribed for her. told her to go home and rest and call in medical aid if she became worse. From that day I saw no more of her. She miscarried, however, and afterwards became seriously ill and she was laid up for weeks with all the symptoms pointing to the poisonous action of lead-viz., gastro-enteritis and colic, maniacal delirium and slight epileptiform convulsions, intense headache with impairment of vision, and such prostration and weakness of the limbs, especially of the arms, that she feared she was going to lose the use of them. She was compelled to call in a medical man but refused to let them fetch me because knew what she had been taking and "went on so to hem about it." The medical man she did call in she tried to delude by ascribing her illness to a chill caught after miscarriage. And $I$ have since been told of other cases where the victims of such folly have been ill for weeks after and have all but made a wreck of their lives. I have no doubb that not a few have been persuaded to take diachylon who would never have done so had they had any idea of its pernicious effects. I have heard of a case where a woman brought on not only miscarriage but following it also partial paralysis of an arm and hand, and this woman, after reading the account of the inquest, wisely exclaimed, "Never again." A friend of mine tells me of a case he saw in the out-patient room of one of the hospitals - a young woman with paralysis in one arm corresponding to the distribution of the ulnars nerve. She admitted having gone through a miscarriage $a_{\Delta}$ week or so previously. This is a case in which one may strongly suspect diachylon to have been the agent in effecting the miscarriage. In the light, then, of the present case I am sure the nature of some of the obscure nervous disorders, with the attendant anæmia, \&c., in women who have admitted miscarriage-cases which now and then come under observation in the out-patient roomwill be readily cleared up. During my tenure some years ago of the appointment of physician for out-patients to the Queen's Hospital in Birmingham 1 can call to mind such cases coming under my observation, the etiology of which was. never satisfactorily explained simply by the fact of miscarriage. What may be the practical outcome of this case: I must leave to the consideration of my readers. Diachylon is in almost every poor man's house ; it is bought in the: mass for the sake of cheapness and ostensibly for outward use only, though we know now to what terrible misuse its inward application has been put by some of the female community. It is, of course, generally used for cuts, sores, and spread on linen as plasters for drawing away the milk from the breasts after parturition. I regret that time and leisure have not given me the opportunity of looking up recent literature on the subject of lead-poisoning, but such as it stands and such as it came under my observation I have sent an account of this case in the hope that from a utilitarian, point of view it may be considered worthy of being placect on record in THE LANCET.

Birmingham.

\section{THE MEASUREMENT OF SUNSHINE AT OUR HEALTH RESORTS.}

\section{BY W. BLACK JONES, M.D., B.S. LOND., D.P.H. R.C.P.S. ENG.,}

RESIDEAT PHYSICIAN, LLANGAMMARCH WELLS SPA.

During the last few years a good deal has been written in the pages of THE LANCET in favour of those health resorts which enjoy a good daily record of sunshine. We have heard much of the value of open-air treatment in many morbid conditions which combines the advantages of a pure air with a maximum of sunlight. "Insolation" is a comparatively new word, meaning the exposure of any given thing to the influences of the light of the sun. The sun both breeds life and kills it. Its influence on the great natural processes concerned in plant life has long been established and that it possesses an influence for good on animal life is also known, but in this case the rationale of 
the process is not so well defined. In plant life, at any rate, the subtle changes which are brought about are due probably axclusively to the actinic rays of the sun and not to the purely luminous rays. The actinic rays are the chemical rars of sunlight which bleach and exert a reducing action, as in its effects upon the sensitised silver plate. Is the action similar on the hæmoglobin which by alternate and complete reduction and oxidation favourably influences the condition of the blood? Sunlight has a well-known inhibitory effect apon the life of pathogenic organisms, and Koch has shown that direct sunlight kills the tubercle bacilli in a few hours and not infrequently in a few minutes. This action is not fully understood, but here again it is probably due to the actinic value of sunlight in effecting some marked shemical change. Those familiar with the ordinary processes of photography know full well how great are the differences between the effects upon a sensitised film of diffused light and direct sunlight. In other words, moisture ias represented in the clouds cuts off much of the actinic power of unobstructed sunlight. It is the same in the effect upon organisms, for whereas, as just stated, direct sunlight kills tubercle bacilli in a few hours or minutes, yet they will live for five or seven days under the influence of diffused daylight or daylight filtered of its active chemical properties by the interposition of clouds. Everybody knows the exhilarating effect of a burst of sunshine in the spring after a dull period in the winter. This effect is probably due not to mere luminosity but to an increased actinic action, a chemical action the precise nature of which we cannot explain but which all the same is very generally felt in the form of invigoration and in taking "a brighter view of things." Indeed, the phrase "a brighter view of things" did we but know refers probably not to luminosity but to an increased activity engendered by the hidden and unquestionable benefits of pure unsophisticated sunshine.

The sunshine recorded at a given health resort, statistics of which of different places have appeared from time to time in the pages of THE LANCET, has hitherto related almost mxelusively to its duration. The intensity of the heat may even be recorded, but the intensity of the light, especially in regard to its actinic value or chemical effects, has been hitherto ignored. To me this appears an important omission if we take as our postulate that it is the actinic rays of the sun, and not the luminous rays, which are responsible for biological action. It is certainly so in plant Iife and we may assume therefore that it is so in animal gife. The duration of sunlight is admirably recorded by the Jordan's Recorder, but not for any practical purpose its intensity. Another sort of record may also be obtained by means of the burning effects of the sun, but this again is not an index of its chemical intensity.

At the meeting of the British Association held in Nottingham in 1893 Dr. S. Rideal communicated a very interesting paper on the Iodine Value of Sunlight in the High Alps. This seems to me to be a method depending essentially upon the actinic value of sunlight since a chemical change is produced and the amount of resulting products of the reaction may be easily estimated. The process depends upon the fact that sunlight liberates iodine from an acidulated solution of potassium iodide. The method is briefly as follows. A solution of potassium iodide is made up containing 20 grammes of the salt per litre. Likewise a solution of diluted sulphuric acid is prepared containing 11.9 grammes ner litre of the pure acid. Lastly, 0.39 gramme of pure powdered arsenious acid is dissolved in a little water containing 1.5 gramme of potassium bicarbonate and then made rup to a litre. In the following experiments 10 c.c. of the potassium iodide solution, together with 10 c.c. of the dilute sulphuric acid, were placed in a stoppered bottle of 50 c.c. sapacity and placed upon a white porcelain plate and exposed to the action of the light. At the end of an hour the bottle is removed and bicarbonate of soda added in sufficient quantity to neutralise the free acid present. The bottle is next placed under a burette containing the arsenic solution. The latter is then run in until the colour of the iodine is completely discharged. I have employed this process (which is a slight modification of the method carried out by Dr. Rideal in the Engadine) at Llangammarch Wells, Central Wales, at different periods of the year and in some instances experiments were also conducted in London at the same time.

The following tables (I., II., and III.) are a synopsis of the results obtained at Llangammarch Wells of exposure of an acidified solution of potassium iodide to sunlight. The results are given in milligrammes of iodine liberated per
100 c.c. of solution used, each exposure beginning at about the hour named below and lasting for one hour. The Roman numerals indicate the hours. In practice 20 c.c. of the equally mixed solutions were used and by multiplying by 5 the results are recorded per 100 c.c.

TABLE I:-Results of all Observations-i.e., Bright Sun, Medium and Cloudy.

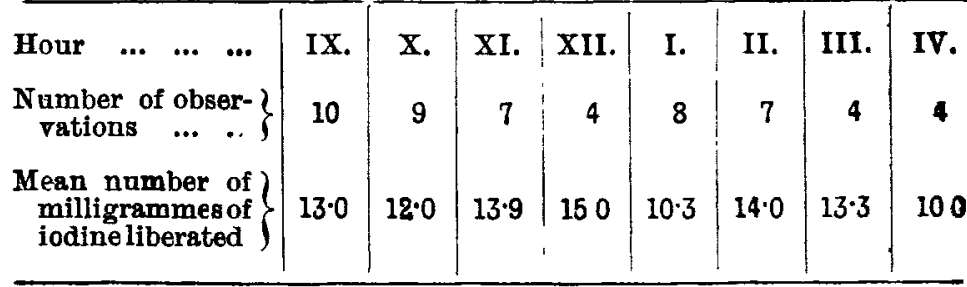

TABLE II.-Results of Observations when the Sun was Shining Brightly for One Hour.

\begin{tabular}{|c|c|c|c|c|c|c|c|c|}
\hline $\begin{array}{llll}\text { Hour } & \ldots & \ldots & \ldots\end{array}$ & IX. & $\mathbf{x}$. & XI. & XII. & I. & II. & III. & IV. \\
\hline $\begin{array}{c}\text { Number of obser- } \\
\text { vations }\end{array}$ & 4 & 1 & 3 & 1 & 2 & 2 & 3 & 1 \\
\hline $\left.\begin{array}{c}\text { Mean number of } \\
\text { milligrammes of } \\
\text { iodine liberated }\end{array}\right\}$ & $15 \cdot 0$ & $14 \cdot 0$ & $14 \cdot 75$ & 150 & 177 & 17.7 & $13 \cdot 6$ & 110 \\
\hline
\end{tabular}

TABLE III.-Result of Observations when the Sun was Completely Clouded for One Hour.

\begin{tabular}{|c|c|c|c|c|c|c|c|c|}
\hline $\begin{array}{llll}\text { Hour } & \ldots & \ldots & \ldots\end{array}$ & IX. & $\mathrm{X}$. & XI. & XII. & I. & II. & III. & IV \\
\hline $\left.\begin{array}{c}\text { Number of obser- } \\
\text { vations ....... }\end{array}\right\}$ & 1 & 2 & 0 & 0 & 2 & 2 & 0 & 1 \\
\hline $\left.\begin{array}{r}\text { Nean number of } \\
\text { milligrammes of } \\
\text { iodine liberated }\end{array}\right\}$ & 4.0 & 10.7 & - & - & 812 & $9 \cdot 25$ & - & 30 \\
\hline
\end{tabular}

These observations were made during the period between May 25th and June 15th, 1897, and were undertaken with the view of ascertaining the variations in one place due to uninterrupted sunlight, cloudy intervals, and an entirely dull day. Two important deductions follow from these interesting records. On a day when the sun was shining brightly and continuously the maximum chemical or actinic effect occurred between one and two o'clock. In the case when the sun was completely clouded the results at the same time of the day showed about one-half of this chemical activity. The information gained in these experiments led me next to try the differences between the sunlight at Llangammarch Wells and at London on the same days. The results were as follows :-

TABLE IV.-The Sunlight of London compared with that of Llangammarch (Summer).

\begin{tabular}{|c|c|c|c|c|c|}
\hline \multirow[t]{2}{*}{ Date. } & \multirow[t]{2}{*}{ Hour. } & \multicolumn{2}{|c|}{$\begin{array}{l}\text { Milligrammes of } \\
\text { iodine liberated per } \\
100 \text { c.c. }\end{array}$} & \multicolumn{2}{|c|}{ Weather observations. } \\
\hline & & London. & $\begin{array}{l}\text { Llangam- } \\
\text { march. }\end{array}$ & London. & Llangammarch. \\
\hline \multirow{6}{*}{$\begin{array}{l}\text { Sept. 10th, } \\
1897 .\end{array}$} & $\begin{array}{l}\text { IX. } \\
\text { X. }\end{array}$ & - & $\begin{array}{l}12 \cdot 25 \\
11 \cdot 50\end{array}$ & - & $\begin{array}{l}\text { Bright, sunny. } \\
\text { Eright, with } \\
\text { cloudy intervals. }\end{array}$ \\
\hline & XI. & $3 \cdot 0$ & $14 \cdot 50$ & $\begin{array}{l}\text { Alternate } \\
\text { sun and } \\
\text { cloud. }\end{array}$ & $\begin{array}{l}\text { Alternate sun } \\
\text { and cloud. }\end{array}$ \\
\hline & XII. & $5 \cdot 5$ & $14 \cdot 75$ & Ditto. & Bright, sunny. \\
\hline & I. & $7 \cdot 0$ & $13 \cdot 5$ & & $\begin{array}{l}\text { Alternate sun } \\
\text { and cloud. }\end{array}$ \\
\hline & II. & $6 \cdot 0$ & $11 \cdot 25$ & Ditto. & $\begin{array}{l}\text { Bright, with } \\
\text { cloudy intervals. }\end{array}$ \\
\hline & III. & $4 \cdot 0$ & 8.05 & All sun. & $\begin{array}{l}\text { Occasionally } \\
\text { bright sun; } \\
\text { otherwise clouds. }\end{array}$ \\
\hline
\end{tabular}

It will appear, therefore, that the conditions being the same the sunlight in London has nothing like the actinio power of the sunlight at Llangammarch Wells, and probably at other places situated under a similarly pure environment. 
The transparency of the air is, of course, the most important factor to be taken into account. In London the air is seldom transparent in the same sense that the air in the country or in Wales is transparent. Llangammarch in particular is situated in a charming part of the country and is sheltered from adverse winds amongst mountain scenery and is very remote from manufacturing centres. On the other hand, London is hemmed in by factories and other places which load the air with dust or smoke, which have a great effect in absorbing the actinic power of the sun's rays. It happened in London within a fortnight of these experiments to be foggy. The first fog, indeed, of the autumn of 1897 occurred on Sept. 27th. The fog was low-lying and the sun could be seen shining through the gloom. A bottle containing 20 c.c. of acidified potassium iodide was exposed from 11 A.M. to 5 P.M., that is, just six hours, with the result that the iodine liberated per 100 c.c. was only 0.5 milligramme or 0.08 milligramme per hour. This is a striking instance of the remarkable effect which fog has of absorbing practically all the actinic rays although light rays still penetrate.

The next experiments were conducted in the winter and fortunately again I was able to carry out similar experiments in Llangammarch and at the same time in London. The results over four days were as follows :-

TABLE V.-The Suntight of London Compared with that of Llangammarch (Winter).

\begin{tabular}{|c|c|c|c|c|c|}
\hline \multirow[t]{2}{*}{ Date. } & \multirow{2}{*}{ 点 } & \multicolumn{2}{|c|}{$\begin{array}{l}\text { Milligrammes of } \\
\text { iodine liberated } \\
\text { per } 100 \text { c.c. }\end{array}$} & \multicolumn{2}{|c|}{ Weather observations. } \\
\hline & & London. & $\begin{array}{c}\text { Llangam } \\
\text { marcb. }\end{array}$ & London. & Llangammarch. \\
\hline \multirow{4}{*}{$\begin{array}{l}\text { Feb. 14th, } \\
1898 .\end{array}$} & $\mathbf{X I}$. & 3.5 & 8.5 & $\begin{array}{l}\text { Sunshine, } \\
\text { bazy. }\end{array}$ & $\begin{array}{l}\text { Bright sun at } \\
\text { intervals. }\end{array}$ \\
\hline & XII. & $5 \cdot 0$ & $7 \cdot 5$ & $\begin{array}{c}\text { Sunshine, } \\
\text { bright. }\end{array}$ & - \\
\hline & I. & $5 \cdot 0$ & $9 \cdot 0$ & , & - \\
\hline & II. & $2 \cdot 5$ & $8 \cdot 0$ & " & - \\
\hline \multirow{4}{*}{$\begin{array}{l}\text { Feb. } 15 t h \text {, } \\
1898 .\end{array}$} & $\mathbf{X I}$. & $1 \cdot 0$ & $4 \cdot 0$ & $\begin{array}{l}\text { Dull ; } \\
\text { cloudy all } \\
\text { day. }\end{array}$ & Fine rain all \\
\hline & XII. & $2 \cdot 5$ & $3 \cdot 0$ & - & - \\
\hline & I. & $1 \cdot 0$ & $2 \cdot 5$ & - & - \\
\hline & II. & $1 \cdot 0$ & $2 \cdot 0$ & - & - \\
\hline \multirow{4}{*}{$\begin{array}{c}\text { Feb. 16th, } \\
\text { 1898. }\end{array}$} & $\mathbf{X I}$. & $5 \cdot 0$ & $2 \cdot 5$ & Bright sun. & Cloudy all day. \\
\hline & XII. & $4 \cdot 5$ & $3 \cdot 0$ & ., & - \\
\hline & I. & $6 \cdot 0$ & $2 \cdot 0$ & ," & - \\
\hline & II. & $4 \cdot 0$ & $2 \cdot 0$ & ", & - \\
\hline \multirow{3}{*}{$\begin{array}{l}\text { Feb. 17th, } \\
1898 .\end{array}$} & IX. & - & $5 \cdot 0$ & $\begin{array}{c}\text { Dull ; } \\
\text { cloudy } \\
\text { and dark. }\end{array}$ & $\begin{array}{l}\text { Sun at first, } \\
\text { then rain. }\end{array}$ \\
\hline & $\mathbf{x}$. & 05 & $4 \cdot 75$ & - & - \\
\hline & XI. & 05 & $2 \cdot 0$ & - & - \\
\hline
\end{tabular}

Here also will be remembered the great superiority of the sunlight at Llangammarch in winter time when the conclitions were meteorologically the same. Thus the maximum amount of ic di je liberated in one experiment at Ilangammarch was 9 milligrammes, whilst the maximum in London under the sam? conditions was 6 milligrammes. In both cases it will be observed that the maximum occurred at the same time between the hours of 1 and 2 o'clock. When it was cloudy all day at Llangammarch the activity of the light was always more than twice that in London under the same conditions.

I have already referred to Dr. Rideal's experiments on the iodine value of sunlight in the high Alps. His results were contained in the British Association Reports, 1893, at Nottingham, and 1894 at Oxford. He found at St. Moritz that the average amount of iodine liberated was 9.34 milliyrammes per 100 c.c. per hour. The maximum hour value was 13.5 milligrammes on Jan. 1st, 1893, and the lowest was 5.7 milligrammes on the $24 \mathrm{th}$ of the same month. In the Grindelwald the average was 8 milligrammes per hour. In 1893, from Dec. 6th to Feb. 28th, 1894, the maximum at St. Moritz was 14.52 milligrammes per hour, the lowest value on Dec. 9th was 3.53 milligrammes, and the average value for the period was 7.05 milligrammes.

I venture to think that these results are very instructive and interesting since they show that at any rate at Llangammarch, and doubtless at other home health resorts, the power and activity of the sun even in the winter is in no sense. inferior to that which falls upon the health resort of very high altitudes like the Grindelwald at St. Moritz. After all, the effect of sunlight must be largely determined by the purity of the air and a measure of the actinic value of sunlight must therefore be to some extent a measure of atmospheric purity. The mountainous districts at home, though not of the scale abroad, are notorious for the crystal transparency and clearness of the air, and the experiments I have made at Llangammarch Wells have: given results which are by no means disappointing, but which, on the contrary, show that as regards open-air treatment and exposure to a sunny air we may count upon certain of our health resorts at bome as providing conditions of an equal value with those in certain places abroad. Some: pertinent remarks of Professor von Ziemssen are quoted by Dr. Arthur Ransome in an article in THE LANCET of June $11 \mathrm{th}, 1898$, especially in regard to the treatment of patients at high altitudes. Professor von Ziemssen concludes that the only advantages in favour of mountain climates are: " the pure dry air, the slight wind in winter." He then pointss out the disadvantages of treatment at high altitudes. Markeds atmospheric changes occur not infrequently (wind, rain, and snow) and are injurious to the patient. They make the acclimatisation of many patients difficult, and patients with high temperatures (especially those who do not reside in the sanatoria) may become decidedly worse. Other objectionsi are the wearisome journey, with all its bad effeets, the separation from the family, the comfortless conditions in severe illness and in case of death; further, the financia anxiety and the economy necessitated. All these have a bad efiect upon the patient. When the advantages and disadvantages are compared the former are not so clear as to indicate the unconditional recommendation of treatment at high altitude. The long journey from Ingland is frequently' undertaken with great distress to the patient.

It seems to me that the medical profession in England have been somewhat behind their continental brethren in bringing forward the probable advantages of our own health resorts. The experiments I have here recorded appear to me to encourage the belief that, after all, we possess health resorts at home which show equal advantages in regard to purity of air and sunlight, and both these are admittedly important factors in the treatment of disease. I hope the publication of this paper will induce others to adopt this method and report the results at other places. Certainly the results obtained at this health resort (Llangammarch Wells), which, according to the indications of the method employed enjoys: the purest of air and the maximum life-giving properties of the sun, are calculated to justify such a step. Llangammarch Wells.

\section{THE PREVENTION OF TUBERCULOSIS.}

Bx F. RUFENAOHT WALTERS, M.D., M.R.O.P. LoND, PFYSTCIAN TO THE NORTH LONDON CONSUMPTION HOSPITAT.

THE new society so auspiciously started in embryo on June 22nd at the meeting at Sir William Broadbent's residence will have many matters to attend to. I may perhaps be permitted here to refer to a few of them.

The spread of tuberculosis depends mainly on two factors:on constitutional deterioration largely due to lack of fresks air and on infection. It can therefore only be successfully combated by educating the public in hygienic methods. Houses are on the whole better drained than formerly, but it is by no means certain that they are better ventilated. Many shops are being reconstructed with absolute disregard for ventilation. Scarcely an office in London keeps its windows sufficiently open, even in summer, and no doubt largely because of the imperfect enforcement of the Smoke Acts. But for this, out-door restaurants might flourish in London as they do in Paris, Stockholm and Copenhagen. Even medical men often fail to appreciate the dangers of vitiated air and are deeply impressed with the risks of open windows in early phthisis. It is quite hopeles: to prevent the spread of tuberculosis without at the same time improving our organisation for its treatment. Phthisis is curable by combined medical and hygienic 